\title{
Research on the Reform of Applied Mathematics in Colleges
}

\author{
Li Qinghua
}

Xi’ An International University, Shanxi, China, 710077

Keywords: Reform, Applied Mathematics, Colleges

\begin{abstract}
Therefore, the teaching reform of mathematics has become a hot topic in many colleges and universities, how to cultivate students' application of mathematical consciousness is a problem that mathematics teachers should study deeply, and the teaching of mathematics in colleges and university is becoming more and more important. It has also become a key measure of teacher's ability to assess.
\end{abstract}

\section{Introduction}

We are all over the people and the parties, everyone has their own experience, lessons and experience, can be published from all aspects of their own views and suggestions, these should be valuable spiritual wealth, it is worth serious to sum up. I would like to take this opportunity today, in the macro aspects of the university mathematics teaching reform to talk about some of the views for your reference. Mathematics is a traditional education curriculum, in the teaching of changing today, the classification of mathematics is also growing in the past, whether it is aerospace, or economics, computer and so the existence of disciplines are inseparable from mathematics, and mathematics also has become the key to solve the problem, in our production and life played an important role. It is one of the essential ways to cultivate the mathematics interest of college students to strengthen the focus of mathematics education and to insist on the sustainable development of mathematics science. The application of mathematics in mathematics class is particularly important in the university whether it is to solve some practical problems or enhance their own knowledge structure has a certain effect, so the application of mathematics teaching reform, schools, teachers and students should strengthen the teaching concept and cultivate students' interest in learning.

\section{Mathematics Teaching Reform}

Start with the word reform. Reform of course means change, which involves three related words: change, improvement and reform. Change the English is change, means a change, but the effect of what is good or bad and did not explain, it should be said that the two possibilities are, so the word is neutral. Improved English is improved, it is clear that the improvement, that is, after the change to become better. This should be a commendatory word, but for a long time to form the habit, often to promote reformism is equivalent to the opposition to the revolution, that is trying to use minor repairs to replace the fundamental changes, the results of "improved" the word becomes a bit gray The In fact, in the normal years, the vast majority of people do most of the useful things can be classified into the improvement of this category, but we do not seem to like this polluted good words, at least feel very fun Not taste We are accustomed to using the word "reform", its English is reform, which prefix "re" has "re-" means, and "form" is "constitute, organization", together is the reconstruction or reorganization, there is a push back, the meaning of another stove. Therefore, the "reform" of the word weight is relatively heavy, should be a relatively large change in action, much stronger than the strength of the improvement. In this sense, we now have written or verbal language, the word "reform" seems to have some abuse of the situation, any one even a very minor change is often called "reform", it seems not so cannot show its importance. In fact, really enough 
to "reform" the title, I am afraid the number is much less. In our math teaching reform, this phenomenon is no exception. In this way, it seems that the words of the scholar's words are just a matter of course, but the reform of mathematics teaching should be carried out in depth, and it is true that the distinction is about the real reform, which is only some improvement, which is only some general of the change, so be aware of the number, do not bearded eyebrows a grasp, or very important. The above phenomenon is a "reform" of the word in the understanding and practice of a misunderstanding, should arouse our attention. There is another misunderstanding about the word "reform" in cognition and practice. As mentioned earlier, reform should be a relatively large or more fundamental change, but literally, the result is good or bad, but we always hope that the reform can bring positive and useful Results, and even bring about revolutionary changes. This reasonable and kind-hearted desire has in fact been attached to the connotation of the word "reform". Now that reform, it should not only be a relatively large or more fundamental change in the action, but also should require it to bring a positive, beneficial results, and even revolutionary changes. Therefore, strictly speaking, the reform should be such a change: it is not only action quite large, and will bring outstanding good results, both indispensable. When we say that one thing is to carry out the reform, we should feel that this is a very heavy argument, to take a very cautious attitude, to effectively take responsibility for the people and the cause and there should be a temporary abyss, a feeling of. It is an irresponsible attitude. Regardless of the consequences, not according to the law, arbitrary to their own and some of the unrealistic ideas imposed on some people, including some of the goods to seize the claws or a little knowledge to sell, the blasphemy of the holy word of reform.

\section{The Present Situation of Applied Mathematics Teaching in Colleges and Universities}

The Application Mathematics Course in Colleges and Universities is the Essential Quality Education Course for College Students. Through the application of mathematics courses, students can cultivate basic computing skills, abstract thinking and logical reasoning ability, analyze and solve problems and continue to learn and apply the ability to create and improve students' mathematical literacy. College Mathematics is the basis for students to learn professional knowledge and skills. Advanced Mathematics is an important part of the curriculum system in the professional training program. It is a course for the follow-up special courses. The Application Mathematics Course in Colleges and Universities is the Carrier to Cultivate Students' Learning Ability. Through this course of study, it helps to develop students 'ability to learn independently, to improve students' basic mathematical literacy.

University of mathematics learning theory is too strong, many students of professional learning is limited to theoretical knowledge, can not be combined with time, in the field of application can not meet the expected requirements, and in the learning process can not be profound understanding, but also greatly less the enthusiasm of learning. Now the university mathematics classroom teaching mostly use the "full house" teaching mode, lack of inquiry and students' active participation, lack of cooperation and communication. It is difficult to realize the employment-oriented, based on the job, pay attention to the quality, strengthen the application, and realize the professional ability of the students, from the perspective of the cultivation of professional talents, but also pay attention to the training of the mathematical skills and the rigorous reasoning process. The use of mathematics teachers plays an important role in teaching, but teachers are less knowledgeable about practical scientific knowledge and are not innovative. In the course of teaching, there is a lack of knowledge, which makes it easy for students to study the subject not deep enough cannot really do the combination of theoretical practice characteristics.

\section{Methods and Strategies of Teaching Reform of Applied Mathematics in Colleges}

The application of mathematics courses in colleges and universities should be based on the practical needs of different professional services, with the principle of moderation and sufficient use to serve the improvement of the comprehensive quality of students. To highlight the cultivation of students' ability, To train students to use mathematical methods to solve practical problems and to 
focus on innovation.

That is, for the needs of different professional and different students, to adopt a flexible curriculum system, but too much emphasis on the overall theoretical system integrity and logical rigor, for professional courses and vocational skills training to provide the necessary, enough basic knowledge With the basic ability to support.

Change the one-way inculcation of teaching methods, and actively explore the heuristic and other diversified teaching methods; change a single teacher teaching, students passive listening to the traditional way, establish a good atmosphere of teacher and student interaction.

The teaching and application of mathematics in colleges and universities are very important to the cultivation of students' mathematics application consciousness and preliminary application ability. To accomplish this important teaching task, we need to know the reason of the poor students' application of mathematical consciousness and improve the students' interest in classroom learning and self-study. Recognizing the breadth of applied mathematics, through the exploration and progress of every math educator, the importance and support of the mass society can really make the students of mathematics majors in colleges and universities have good application consciousness and ability. Whether students are interested in mathematics mainly depends on our teaching practice, and our teaching content and teaching methods of choice and application are closely related. Cultivating students' ability of "using mathematics" is the fundamental task of mathematics education, and of course should be the "top priority" in the purpose of mathematics application teaching. To highlight the application of mathematics, we should stand on the height of building a mathematical model to recognize and implement the application of teaching, to more emphasis on how to find and abstract from the practical problems of mathematical problems, and then try to use the existing mathematical model to solve the problem, and finally Using the results to explain this practical problem, which is teaching a "practical - theoretical - practical" strategy.

I am quite skeptical about the practice of combining geometry and algebra in a first year in college. It is true that the combination of geometry and algebra, in the history of mathematics, Cartesian creation of analytical geometry is a groundbreaking event, but also contributed to the invention of calculus and the rise of modern mathematics, the significance is very significant. For those who are familiar with geometric and familiar algebra, find and point out that this connection, in the knowledge is undoubtedly a deepening, can bring enlightened, suddenly see the feeling. However, the first year of college students, in both algebra and geometric lack of adequate training, the basis of a very weak case, not their first geometric and algebra in terms of careful teaching and rigorous training, so that they in these two They have a good foundation, and all of a sudden they want to accept geometric and algebra combination of teaching system, it is difficult to make them truly appreciate the geometric and algebra combined with the advantages and mysteries, will weaken them The understanding and mastery of the two disciplines of geometric and algebra are probably a hasty way of doing so, and they do not conform to them from shallow to deep, from the table and to the law of cognition. This approach, the objective effect is likely to replace the geometry with algebra. Nowadays, the obvious lack of structural errors in the teaching of mathematics in the university is the serious weakening of geometric training, which leads to the shortage of students' geometric knowledge, the weak geometric concept and the lack of geometric thinking. This is the problem that should pay serious attention in the reform of mathematics teaching, and the occurrence of the problem may be geometric and algebra at the beginning of the combination of teaching has been exposed. Linked to the serious lack of geometric training in college students, this is not just a matter of students to understand the law of the law.

\section{Conclusion}

How to improve students' learning ability in teaching is the first thing to be aware of. The application of mathematics is not very monotonous compared to pure mathematics, so it is relatively easy to cultivate interest compared with pure mathematics. Colleges and universities should increase the application of mathematics teaching investment, continuous in-depth study and improve the overall level of teachers and quality, the application of mathematical development to a 
new level. This is a rich treasure, is a promising career, do not hold gold rice bowl begging, blindly know only from abroad to something to come in, but based on the land in China to seize this rich characteristics of our research mathematics teaching reform to do some really meaningful basic work. To do so, is the merit of the infinite, we hope that we all work together.

\section{References}

[1] Chen Chunzhi, Chen Jie. Application of mathematical awareness of the training[J]. Science and education. 2008 (08)

[2] Liu Yuliang, Shi Lvwen.There are some problems and countermeasures in the teaching reform of mathematics curriculum in colleges and universities [J]. Chinese Adult Education. 2007 (13)

[3] Meng Xiaoling. Combining the characteristics of contemporary college students to carry out the reform of mathematics teaching[J]. Teaching and learning. 2007 (03)

[4] Chen Baoshan, Wang Yunmian. On the reform of mathematics teaching in colleges and universities[J]. Journal of Changchun University of Science and Technology (Social Science Edition). 2005 (03)

[5] Han Guoqiang. Application of mathematics teaching experience[J]. Journal of Zhengzhou Railway Vocational and Technical College. 2004 (01) 